\title{
CLÍNICA PSICODINÂMICA DO TRABALHO COM GESTORES DE UMA UNIDADE DE TAQUIGRAFIA PARLAMENTAR
}

\author{
Clinical Psychodynamics Of Work With Managers Of Parliamentary Shorthand \\ Clinique Psychodynamique Du Travail Avec Les Gestionnaires D'une Unité De Sténographie \\ Parlementaire
}
Clínica Psicodinámica Del Trabajo Con Gestores De Una Unidad De Taquigrafía Parlamentaria

\begin{abstract}
Emílio Peres Facas 1
Profess or Adjunto da Universidade de Brasília. Colaborador dos Programas de Pós -Graduação em Psicologia Social, do Trabalho e das Organizações (UnB) e em Psicologia da Faculdade de Educação (UFG). Psicólogo,

Doutor em Psicologia Social, do Trabalho e das Organizações pela Universidade de Brasília com período sanduíche em Université Catholique de Louvain. Coordenador do Laboratório de Psicodinâmica e Clínica do

Trabalho - LPCT/UnB.
\end{abstract}

Héden Cardoso Rodrigues Fischer ${ }^{2}$

Psicóloga no Projeto Práticas em Clínica do Trabalho do Centro de Atendimento e Estudos Psicológicos do Instituto de Psicologia da UnB. Pesquis adora do Grupo de Estudos e Práticas em Clínica, Saúde e Trabalho GEPSAT. Membro do Laboratório de Psicodinâmica e Clínica do Trabalho da Universidade de Brasília - UnB (convidado). Atendimento em Clínica do Trabalho (Consultório de Psicologia). Mestre em Psicologia Social e do Trabalho pela UnB. Especialista em Psicodinâmica do Trabalho pela UnB.

Liliam Deisy Ghizoni ${ }^{3}$

Profes sora da Universidade Federal do Tocantins - UFT - Campus Universitário de Palmas, no Curso de

Administração e no Programa de Pos Graduação em Comunicação e Sociedade (PPGCOM). Doutora em Psicologia Social do Trabalho e das Organizações na UnB com Estágio Sanduíche na Université Catholique de Louvain la Neuve - Bélgica. Pesquisadora do Laboratório de Psicodinâmica e Clinica do Trabalho - LPCT/UnB. No CNPQ é líder do Trabalho e Emancipação: coletivo de pesquisa e extensão (UFT) e também membro do Grupo de Pesquisa Psicodinâmica e Clínica do Trabalho (UnB). Membro do GT Psicodinâmica e Clínica do Trabalho na ANPEPP.

\section{RESUMO}

É apresentada uma prática em clínica Psicodinâmica do Trabalho com gestores da área de taquigrafia de uma organização pública. Foram feitas nove sessões coletivas comoito gerentes. Concluiu-se que os participantes estão submetidos a uma organização do trabalho focada na produtividade e na excelência da prestação dos serviços. Não há espaço para a subversão do trabalho prescrito e flexibilidade no modo de conduzir as tarefas. Há espaço de negociação para solucionar os problemas advindos do trabalho real, permitindo que o gerente coloque a

\footnotetext{
${ }^{1}$ E-mail: emiliopf@gmail.com

2 E-mail: hedenfischer@gmail.com

${ }^{3}$ E-mail: 1dghizoni@gmail.com
} 
criatividade e a subjetividade para lidar com o prescrito. A possibilidade de enfrentar os constrangimentos do trabalho dá espaço às vivências de prazer, que são intensificadas pelo reconhecimento no trabalho.

Palavras-chave: Psicodinâmica do Trabalho; Gerente; Taquigrafia; Excelência na Gestão.

\begin{abstract}
It performed the clinical work with managers in the field of shorthand, a public organization, the approach of psychodynamic work. Nine group sessions were conducted with eight managers, recorded and submitted to psychodynamic analysis. It was concluded that managers are subject to a labor organization focused on productivity and excellence of service delivery. There is no room for subversion of the prescribed work and flexibility in the way of doing things. There is room for negotiation to solve the problems arising from real work, allowing the manager to put creativity and subjectivity to handle the requirements. The ability to meet the constraints of the work gives way to experiences of pleasure, which is intensified by the recognition in the workplace. Advances the field of clinical work and opens pers pectives for future studies.
\end{abstract}

Keywords: Psychodynamics of Work; Manager; Shorthand; Management Excellence.

\title{
RÉSUMÉ
}

Il est présentée ici une pratique en Clinique Psychodynamique du Travail avec les gestionnaires de la zone de sténographie d'une organisation publique. Il a tenu neuf séances de groupe avec huit gestionnaires. Il a été conclu que les participants sont soumis à une organisation du travail concentrée sur la productivité et surl'excellence de la prestation des services. Il n'y a pas d'espace pour la subversion du travail prescrit et flexibilité afin d'accomplir les tâches. Il y a espace de négociation pour résoudre les problèmes résultants du travail réel, ce qui permet au gestionnaire de mettre la créativité et de la subjectivité pour faire face au prescrit. La possibilité d'affronter des contraintes de travail donne lieu à des expériences de plaisir, qui sont renforcées par la reconnais sance au travail.

Mots-clés: psychodynamique du travail; gestionnaire; sténographie; Excellence en gestion.

\section{RESUMEN}

Se presenta una práctica en clínica Psicodinámica del Trabajo con gestores del área de taquigrafía, de una organización pública. Se realizó nueve sesiones colectivas, con ocho gerentes. Se concluyó que los participantes están sometidos a una organización del trabajo enfocada en la productividad y excelencia de la prestación de los servicios. No hay espacio para la subversión del trabajo prescrito y flexibilidad en el modo de realizar las tareas. Hay espacio de negociación para solucionar los problemas reales del trabajo, permitiendo que el gerente coloque la creatividad y subjetividad para lidiar con lo prescrito. La posibilidad de enfrentar los constreñimientos del trabajo da espacio a las vivencias de placer, que se intensifica por el reconocimiento en el trabajo.

Palabras-Clave: Psicodinámica del Trabajo; Gerente; Taquigrafía; Excelencia en la Gestión

\section{INTRODUÇÃO}

No decorrer dos últimos anos as empresas têm criado e adotado modos de gerenciamento do trabalho, para fazer frente às mudanças no contexto empresarial, cujo objetivo é o de obter melhoria no desempenho organizacional, visando $\mathrm{o}$ aumento da produtividade e garantir a competitividade no mercado, tendo como consequência danos irreparáveis à saúde e à vida dos trabalhadores. Há um incremento do sofrimento psíquico, evidenciado pela precarização das condições e das relações no trabalho, além de registros epidemiológicos de inúmeras patologias relacionadas ao trabalho (Freitas, 2006; Dejours, 2008; Martins, 2009; Siqueira, 2009; Eberle, Soboll \& Horst, 2010).

A erosão das estratégias coletivas de defesa e a desestruturação das formas clássicas de solidariedade são os aspectos que mais contribuem para o adoecimento no contexto atual do trabalho. O sofrimento no trabalho é vivenciado quando a organização do trabalho é marcada pelo individualis mo, pela falta de solidariedade, concorrência generalizada, rivalidade e mobilização do medo. O mal-estar da gestão atinge também 
as fileiras da hierarquia intermediária (Dejours, 2008; Martins, 2009; Ramos, 2013).

O sofrimento dos gestores é fortemente influenciado por aspectos referentes ao medo de demonstrar seus fracassos, fraquezas e incompetência. Para enfrentar o sofrimento e o medo os gerentes mobilizam mecanismos de defesa, como o "cinismo viril e a servidão voluntária", e adotam práticas inseridas no próprio modo de gestão da organização que inclusive fazem parte da cultura da instituição, como "o assédio moral organizacional" (Dejours, 2008; Eberle et al., 2010).

Parte-se do pressuposto de que há sofrimento e adoecimento dos trabalhadores que exercem a função gerencial, advindo das contradições inerentes ao papel gerencial e às práticas de gerenciamento adotadas pelas organizações. Por um lado, o gerente tem o papel de estar a favor das políticas e práticas adotadas pela organização, bem como ser o protagonista de práticas que promovem o assédio moral organizacional, como a avaliação individual do trabalho e a gestão da qualidade total. Por outro lado, o gerente está sujeito a um contexto de insegurança e instabilidade no emprego, provocado pelo exercício destas práticas, que se constituem como coerções que perturbam as relações de trabalho e têm como efeito: a vivência de sofrimento, a mobilização de estratégias de defesa e processos de adoecimento do trabalho (Dejours, 2008; Dejours \& Bégue, 2010; Eberle et al., 2010; Ramos, 2013).

Neste estudo é realizada uma prática em Clínica Psicodinâmica do Trabalho com o objetivo de realizar a análise clínica do trabalho. Especificamente objetiva-se discutir os dispositivos para esta prática clínica; analisar a psicodinâmica do trabalho em si e fazer a análise clínica da mobilização do coletivo de trabalho dos gerentes.

Esta prática clínica é baseada no referencial teórico da Psicodinâmica do Trabalho, preconizado Christophe Dejours cujos estudos estão centrados nos efeitos do trabalho sobre os processos de subjetivação, as patologias sócio-psíquicas e a saúde dos trabalhadores (Mendes, 2007, 2008; Facas, 2009; Mendes \& Morrone, 2010). Entretanto sofreu adaptações metodológicas, como já pontuado por Duarte (2014) e Ghizoni, Mendes e Corgozinho (2013).

A Psicodinâmica do Trabalho faz parte de um conjunto de teorias com foco no estudo da relação entre trabalho e subjetividade, denominadas por Bendassoli \& Soboll (2011) como "Clínicas do Trabalho" que estão baseadas nos seguintes pressupostos: 1. o interesse pela ação no trabalho, no sentido de resgatar o poder de agir do trabalhador; 2. o entendimento sobre o trabalho como uma atividade sustentada por um projeto de transformação do real e da construção de significados pessoais e sociais; 3. o indivíduo é visto considerando o contexto do trabalho, ou seja, todas as forças dinâmicas que afetam a relação sujeito e trabalho; o seu propósito consiste em pensar a relação sujeito e trabalho.

Segundo Mendes (2007) é objeto da Psicodinâmica do Trabalho o estudo das relações dinâmicas entre organização do trabalho e processos de subjetivação, que se manifestam nas vivências de prazersofrimento, nas estratégias de ação para mediar contradições da organização de trabalho, nas patologias sociais, na saúde e no adoecimento. A Psicodinâmica do Trabalho também se caracteriza como um modo de ação na organização do trabalho, visto que dá acesso às dinâmicas internas que ocorrem no espaço público de discussão, de modo a abrir a possibilidade de (re) construção dos processos de subjetivação e do coletivo.

No Brasil, a prática da Clínica Psicodinâmica do Trabalho é relativame nte recente e tem por base o método originalmente proposto por Dejours (1992), vinculado à Psicopatologia do Trabalho e influenciado pela Ergonomia, com e sem adaptações à realidade brasileira (Heloani \& Lancman, 2004; Duarte, 2014; Ghizoni, Mendes e Corgozinho, 2013). 
No livro "Clínica Psicodinâmica do Trabalho: O sujeito em ação", Mendes \& Araújo (2012) sistematizam aspectos relevantes da prática atualmente adotada, baseados nas pesquisas e intervenções realizadas entre 2009 a 2011 no Laboratório de Psicodinâmica e Clínica do Trabalho (LPCT) na Universidade de Brasília $(\mathrm{UnB})^{4}$, sendo denominada de Clínica Psicodinâmica do Trabalho. Pontua-se ainda que práticas clínicas como a de Ghizoni e Mendes (2014a) e Ghizoni e Mendes (2014b) foram marcos de mudanças metodológicas, culminando na publicação de Mendes (2014) que descreve alterações substanciais na metodologia das escutas clínicas, baseando a Psicodinâmica do Trabalho e sobretudo a Psicanálise como aporte teórico. Estes novos escritos de Mendes (2014) avançam e diferem em algumas questões metodológicas realizadas neste estudo com os gestores de uma unidade de taquigrafia parlamentar, pois se guiou em Mendes e Araujo (2012).

Neste cenário o presente estudo constitui uma importante contribuição no avanço das pesquisas em Psicodinâmica do Trabalho, vez que não foram identificados estudos envolvendo escutas clínicas com trabalhadores que exercem a função gerencial, apesar do considerável volume de estudos realizados em uma diversidade de profissões, no campo da Psicodinâmica do Trabalho (Mendes \& Morrone, 2010; Ghizoni \& Mendes, 2014b). Considerando a força do papel gerencial nas mudanças organizacionais, a Clínica Psicodinâmica do Trabalho, enquanto espaço de escuta, reflexão e discussão poderá instigar o resgate das estratégias coletivas e a reestruturação das formas de solidariedade no contexto organizacional.

\section{MÉTODO}

\footnotetext{
${ }^{4}$ As publicações (artigos, dis sertações e teses) deste laboratório podem ser acessadas no site: www.lpct.com.br

${ }^{5}$ Esta escolha de supervisão a cada três sessões não funcionou em outras práticas clínicas, tudo depende
}

Esta pesquisa teve como método de investigação e ação a Clínica Psicodinâmica do Trabalho, ou seja, a escuta do sofrimento psíquico dos trabalhadores, proposta por Mendes \& Araújo (2012).

Segundo as autoras, o coletivo do trabalho é especificidade do método. O termo Clínica Psicodinâmica do Trabalho busca integrar a ação na clínica, ao articular a ação no ato da linguagem. Neste caso, o processo de eleboração-perlaboração da fala pelo coletivo permite a passagem do espaço de discussão para o espaço de deliberação. É no produzir e no viver junto que se viabiliza a mobilização subjetiva, que permitirá a transformação da organização do trabalho, bem como da relação subjetiva do trabalhador com o seu trabalho. É uma prática que inclui a pesquisa e a intervenção como dimensões indissociáveis.

A demanda para a realização de uma pesquisa sustentada na abordagem da Psicodinâmica do Trabalho se deu por iniciativa da instituição considerando o expressivo número de trabalhadores com histórico de adoecimento na Unidade de Taquigrafia. Os gerentes foram convidados a participar do atendimento clínico coletivo, por e-mail. O número de vagas foi restrito a dez participantes. As sessões ocorreram na própria sala da direção da Unidade de Taquigrafia, no horário de expediente, uma vez na semana, com duração de uma hora e meia, e concluiu-se em nove (09) encontros. Todas as sessões realizadas foram gravadas e posteriormente transcritas.

As sessões foram conduzidas por dois psicólogos e uma estagiária (estudante de Psicologia), que integraram o coletivo de pesquisa, com a supervisão de uma clínicapesquisadora experiente em Clínica Psicodinâmica do Trabalho, realizada a cada três sessões ${ }^{5}$. Um dos clínicospesquisadores possui formação e ampla

da experiência dos clínicos-pesquisadores, entretanto, sugere-se que sejam semanais, para auxiliar nas interpretações que irão nortear o memorial. 
experiência na Área de Saúde no Trabalho e Clínica Psicanalítica e o outro na área da Psicologia das Organizações - Gestão e Mudança Organizacional. Esta pesquisa se constitui a primeira experiência em "Clínica Psicodinâmica do Trabalho" dos clínico spesquisadores que conduziram a escuta.

\section{Participantes}

Para participação na Clínic a Psicodinâmica do Trabalho, os sujeitos deveriam candidatar-se voluntariamente e o grupo se restringiria aos gerentes da Unidade de Taquigrafia. Conforme número mínimo recomendado por Mendes (2007), o estudo foi realizado com oito (08) trabalhadores da carreira gerencial, do setor público, da unidade de taquigrafia, sendo três (03) do sexo masculino e cinco (05) do sexo feminino, com idade entre trinta $\mathrm{e}$ cinquenta anos, com mais de dez (10) anos de serviço público. $\mathrm{O}$ número de participantes ao longo das sessões variou entre quatro a sete. Nenhum dos integrantes estava adoecido no momento de ingresso no grupo. Todos os gerentes já haviam passado por todas as atividades operacionais da Unidade de taquigrafia ao longo de sua experiência profissional na Instituição pública - apanhamento taquigráfico (apanhamento no Plenário e roteiro das Comissões), revisão do registro taquigráfico e supervisão da redação final.

\section{Procedimentos $\quad$ instrumentos metodológicos}

Foram adotados os procedimentos metodológicos sistematizados por Mendes \& Araújo (2012), embora nem todos os itens foram possíveis de discussão. São eles:

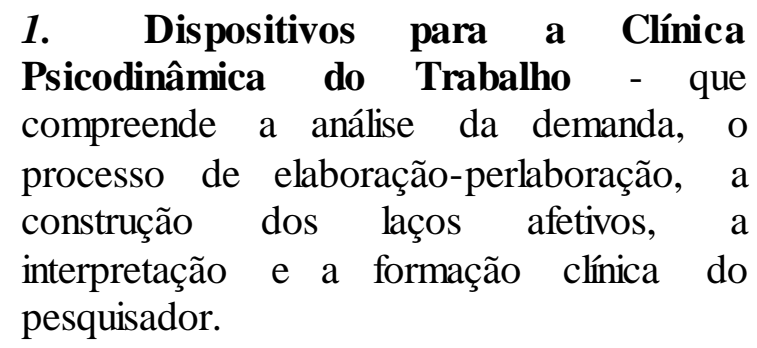

\section{As condições para fazer a clínica} organização da pesquisa - que abarca a construção e análise da demanda; a instituição de regras de conduta do coletivo de pesquisa e do coletivo de supervisão; a constituição do espaço da fala e da escuta; a estruturação do memorial; a restituição e deliberação; o diário de campo e registro dos dados; a supervisão; a apresentação dos relatos e a avaliação.

No processo de organização e análise da demanda da pesquisa foi feita a reunião com servidora que demandou $\mathrm{o}$ trabalho da Clínica e com o Diretor da Unidade de Taquigrafia de modo a obter autorização para realizar o trabalho, a clarificar a demanda, bem como definir os procedimentos relativos ao convite aos participantes e às sessões de clínica propriamente dita. Neste momento foi negociada a realização de dois grupos de Clínica Psicodinâmica do Trabalho: um grupo com os taquígrafos que realizam o apanhamento, e, outro com os todos os gerentes da unidade de taquigrafia. Ressalte-se que a Clínica Psicodinâmica do trabalho com os taquígrafos foi realizada mediante condução por outro pesquisador, tendo a primeira autora como copesquisadora, sendo objeto de outro projeto específico (Alves, 2014).

Concluídos os procedimentos de organização da pesquisa foi realizada reunião com os Gerentes para apresentar o tema, a abordagem da pesquisa, os objetivos, a duração, os procedimentos metodológicos, os participantes e os prérequisitos para a condução do projeto. Neste momento os clínicos-pesquisadores esclareceram que a participação dos servidores deveria ser voluntária. Nesta reunião ficou decidido que o Diretor da Taquigrafia também participaria do grupo de Clínica Psicodinâmica do Trabalho.

Na primeira sessão foram acordadas as regras do coletivo de pesquisa em relação ao sigilo, a gravação das sessões, além do papel dos participantes e dos clínicospesquisadores. Foi assegurado que as falas 
e acontecimentos seriam compartilhados somente entre os clínicos-pesquisadores e a supervisora, e que, se em algum momento quisessem falar algo que não devesse ser gravado, bastaria solicitar que os clínicospesquisadores desligassem o gravador. Foi esclarecido que se estabeleceria um relacionamento igualitário entre os participantes, que o foco consistiria no diálogo sobre o trabalho dos gerentes da taquigrafia, e que os clínicos-pesquisadores não poderiam agir nem tomar decisões pelo grupo, visto que o poder de mobilização é do grupo.

Em seguida deu-se início à sessão de Clínica Psicodinâmica do Trabalho a partir de roteiro preparado pelos clínicospesquisadores contemplando: a organização do trabalho, os sentimentos relativos ao trabalho, as estratégias de mediação presentes no coletivo e os processos de adoecimento e de saúde na organização.

Durante os primeiros encontros os clínicos-pesquisadores trabalharam na criação de laços afetivos entre os integrantes, que consiste em gerar um ambiente de confiança. Na medida em que a confiança era estabelecida os sujeitos se dispunham a expressar os sentimentos em relação às suas vivências de prazer e/ou sofrimento no trabalho.

Após cada sessão os clínicospesquisadores elaboravam o Memorial com o registro escrito das falas dos trabalhadores e das interpretações feitas em supervisão (ou entre os clínicos-pesquisadores), bem como registravam as suas impressões e sentimentos no Diário de Campo, incluindo eventos não verbais e fatos ocorridos no coletivo de pesquisa, de forma a subsidiar a supervisão e a posterior Análise Clínica do Trabalho (ACT).

Na sessão subsequente os clínicospesquisadores davam início à "Restituição e Deliberação" mediante leitura do memorial. Os integrantes avaliavam a adequação do registro e das interpretações. Os gerentes raramente discordavam dos aspectos retornados. Geralmente a sessão continua va abordando-se temas complementares ao
Memorial, abrangendo assuntos da organização do trabalho, as dificuldades e sentimentos em relação ao trabalho, as estratégias de mediação para lidar com o sofrimento e as patologias decorrentes. E assim as sessões de Clínica Psicodinâmica do Trabalho decorreram até o último atendimento.

As sessões de supervisão consistiam de análise e discussão dos registros do Memorial e do Diário de Campo, complementadas pela leitura de trechos das transcrições das sessões. A supervisora destacava atos falhos que passavam despercebidos, falas sobre os sentimentos que deveriam ter sido mais incentivadas ou, ainda, perguntas feitas em momentos inadequados, que provocavam mudança de assunto. Em seguida apontava os aspectos que deveriam ser ajustados, considerando os referenciais da Psicanálise.

\section{Procedimentos de Análise dos Dados}

Em relação aos procedimentos de análise dos dados, Mendes \& Araújo (2012) propõem o uso da técnica denominada "Análise Clínica do Trabalho (ACT)" para organizar o material coletado nas sessões coletivas e realizar a análise da Psicodinâmica do Trabalho. Esta técnica tem por base a qualidade e o significado do discurso. As verbalizações são analisadas no coletivo, considerando as contradições e paradoxos da linguagem. Todas as sessões são analisadas de modo articulado, visando identificar a evolução, o aprofundamento e as especificidades das discussões coletivas. É a ACT que norteia os resultados deste estudo.

A Análise Clínica do Trabalho é composta por três etapas:

1. Apresentação dos Dispositivos para a Prática Clínica originados do registro no memorial e diário de campo.

2. Análise da Psicodinâmica do Trabalho registrada nas transcrições das sessões ou registro das falas, organizada em três eixos: 
a) Eixo I - Organização do Trabalho - conteúdo das tarefas, normas e controles, tempos e ritmos, relações sócioprofissionais, comunicação e métodos de gestão;

b) Eixo II - Mobilização Subjetiva - inteligência prática, espaço de discussão, cooperação, reconhecimento;

c) Eixo III - Sofrimento, defesas e patologias - sofrimento criativo, sofrimento patogênico, defesas (mecanismos e modos de manifestação), tipos de patologias, danos físicos e psicossociais.

\section{Análise Clínica da Mobilização do} Coletivo de Trabalho que compreende a articulação entre os dispositivos para a clínica (etapa 1) e a análise da psicodinâmica (etapa 2). Ressalte-se que para cada uma das dimensões da organização do trabalho devem ser analisadas suas relações com o sofrimento, as defesas, as patologias e a mobilização subjetiva.

\section{RESULTADOS}

Na primeira e segunda sessão a fala foi centrada no tema da Organização do Trabalho. Nas sessões seguintes os participantes complementaram a descrição da Organização do Trabalho, bem como expressaram as vivências de sofrimento e prazer, algumas estratégias de mediação e as patologias decorrentes. Quanto aos elementos da mobilização subjetiva as falas concentraram-se no reconhecimento no trabalho. Na escuta surgiu também o relato de um caso de assédio moral no trabalho, vivenciado por um dos integrantes, no passado distante.

A primeira sessão da Clínica Psicodinâmica do Trabalho teve início com um clima tenso entre os participantes. Entre a terceira e quarta sessão, parte da fala do grupo concentrou-se no movimento interno do Órgão, em torno da substituição do então
Diretor da Taquigrafia e nos sentimentos dos integrantes em relação às mudanças. A substituição se confirma na quarta sessão, a qual o Diretor não participa do grupo em função do anúncio de sua saída do cargo, dias antes.

$\mathrm{Na}$ quinta sessão a nova diretora participa prontamente do grupo, que a recebe de modo positivo. A participação da nova diretora traz novos temas e um novo ambiente para o grupo, com foco na expressão das vivências de sofrimento e patologias, no entanto, não se constatou mobilização por parte dos integrantes. Considerando a fase de transição da direção da unidade de taquigrafia, entre a quarta e nona sessões houve cancelamento de 05 sessões da Clínica, sendo que entre a oitava e nova foram canceladas 03 sessões, a pedido da Instituição.

Percebendo a dificuldade do grupo em mobilizarem-se diante das vivências de sofrimento no trabalho, na sétima sessão, os clínicos-pesquisadores levaram o Mito de Sísifo, que recebe o castigo de empurrar uma pedra até o lugar mais alto da montanha, de onde ela rola de volta, cabendo a Sísifo a tarefa de empurrá-la novamente morro acima. Fez-se uma adaptação metodológica, não descrita por Mendes e Araujo (2012), quando se utilizo u imagens que simbolizavam a pressão no trabalho gerencial, assunto frequentemente trazido pelos Gerentes.

$\mathrm{Na}$ oitava sessão de Clínica Psicodinâmica do Trabalho um dos integrantes revela que o Diretor anterior os convocou, de modo sutil, a participar do trabalho, embora a equipe de clínicospesquisadores o tenha alertado de que os servidores não poderiam ser convocados e sim convidados a colaborar com a pesquisa. A nova Diretora não participou da oitava sessão.

$\mathrm{Na}$ nona e última sessão os participantes verbalizaram que a maior dificuldade da participação na Clínica Psicodinâmica do Trabalho foi o volume de demandas na Unidade de Taquigrafia. $O$ gerente coordena diversas frentes de 
trabalho, há pressões para realizar o trabalho com qualidade e dentro de prazos restritos. Os Gerentes relataram que sentiam angústia pelo acúmulo de trabalho: "Estamos aqui na Clínica Psicodinâmica do Trabalho e o serviço do cotidiano está nos esperando. Sentimos que não estamos produzindo".

A Unidade de Taquigrafia é responsável pelo registro, revisão e redação final de pronunciamentos e debates nas sessões Plenárias da Instituição, nas reuniões de Comissões e outros eventos. A sua estrutura é composta pela Diretoria da Unidade, que conta com o suporte de uma Assessoria Técnica e o Serviço de Administração, que atende à toda Unidade de Taquigrafia. Está subdivida em 04 Coordenações: a de Registro Taquigráfico, a de Revisão, a de Redação Final e a de Histórico de Debates.

A seguir apresentam-se os resultados da Análise Clínica do Trabalho. Importante destacar que nem todos os elementos desta análise puderam ser trabalhados, seja por inexperiência dos clínicos-pesquisadores, seja por esta prática clínica ter sido realizada concomitante a construção do método descrito por Mendes e Araujo (2012).

\section{Dispositivos para a prática Clínica}

Acredita-se que a prática clínica ficou limitada devido ao modo de estruturação da demanda e a construção dos laços de confiança. A demanda se deu por iniciativa de uma servidora da unidade de taquigrafia, considerando o aumento do adoecimento no trabalho, no grupo de taquígrafos. $\mathrm{O}$ trabalho com os gerentes foi demandado pelo diretor da unidade de taquigrafia, que convocou os gerentes a participar do trabalho. Deste modo, o requisito do voluntariado foi violado.

A criação de laços de intimidade e de confiança pode ter sido prejudicada pelo receio dos gerentes em expor as falhas diante dos pares, o que os leva a colocar em cheque a sua competência, incompatível com a premissa da excelência do serviço prestado.

Em linhas gerais os gerentes focaram as suas falas em aspectos que justificam a organização do trabalho e o alcance da excelência. Havia uma repetição em torno deste aspecto. A mobilização do eu dos gerentes não aconteceu, não houve ressonância do discurso do outro e, portanto, a transferência entre os participantes. A nomeação do sofrimento, das estratégias de defesa e patologias possibilitou apenas o apontamento dos aspectos a serem observados pelos gerentes com maior profundidade, de modo a evitar $\mathrm{o}$ adoecimento.

\section{A Psicodinâmica do Trabalho dos Gerentes}

\section{Organização do Trabalho}

Em relação à Análise Psicodinâ mic a do Trabalho, no eixo Organização do Trabalho constatou-se que o gerente é responsável pela coordenação das atividades de sua Unidade - Direção, Registro, Revisão, Redação Final e Histórico - abrangendo o planejamento e o acompanhamento dos trabalhos, para garantir que todo o processo produtivo ocorresse conforme as prescrições de excelência definidas. No real atua como um "solucionador de problemas", e muitas vezes, na linha execução do trabalho operacional, para que o trabalho seja realizado dentro do prazo e a qualidade esperada.

A organização do trabalho é geradora de sofrimento e prazer. Observouse pouca flexibilidade no modo de realizar as tarefas, entretanto há espaço de negociação para solucionar os problemas advindos do real do trabalho, o que permite ao Gerente colocar a sua criatividade e a sua subjetividade para lidar com a realidade imposta pela organização. Neste caso, a possibilidade de enfrentar as imposições e pressões do trabalho dá espaço às vivências 
de prazer, que é intensificada pelo reconhecimento no trabalho, visto que a Unidade de Taquigrafia é reconhecida interna e externamente pela excelência no serviço prestado.

\section{Mobilização Subjetiva}

Constatou-se que a mobilização subjetiva ocorre pela dinâmica do reconhecimento. Apesar do sofrimento vivenciado pelas pressões no trabalho, os gerentes identificam-se com a profissão de taquígrafo, além de ter orgulho pelo que fazem vez que há reconhecimento institucional da utilidade do trabalho, bem como o reconhecimento externo quanto a beleza do trabalho, por outras unidades de taquigrafia, no âmbito nacional e internacional.

O prazer no trabalho é reforçado pela possibilidade de contato direto com autoridades e personalidades políticas, nacionais e internacionais; pelo sentimento de realização por contribuírem para a construção da história do Brasil; e, pela autonomia na condução dos trabalhos, concretizada pela liberdade em buscar soluções para os problemas do cotidiano e manter o padrão de excelência esperado.

\section{Sofrimento, defesas e patologias}

Os gerentes estão expostos às pressões no trabalho oriundas de diversos focos:

1. Das relações sócio-profissio na is (subordinados, gerentes das áreas internas da Unidade, superiores hierárquicos, deputados e senadores, comissões técnicas, órgãos da casa, cidadãos, imprensa);

2. Das condições de trabalho consideradas não ideais;

3. Da conformidade em relação às normas e controles.

Os gerentes sentem:
1. Angústia quanto as mudanças constantes na hierarquia da instituição pública;

2. Raiva e frustração quando Dirigentes da casa engavetam propostas de inovações;

3. Falta de capacidade de ação diante da falta de apoio das áreas-meio na viabilização dos recursos, da falta de compreensão e compromisso de alguns servidores com o trabalho, das reclamações infundadas por parte dos taquígrafos $\mathrm{e}$ clientes internos.

A grande responsabilidade imputada ao trabalho gerencial pela Organização do Trabalho foi muito verbalizada. Há um medo de errar considerando o padrão de excelência estabelecido e os danos políticos causados, o que é motivo de sofrimento. Também é gerador de sofrimento a sobrecarga de trabalho vivenciada pelos taquígrafos e o sentimento de impotência diante da adoção de ações estruturantes para solucionar os problemas de falta de pessoal e de recursos suficientes para atender o volume das demandas, visto que está na alçada da hierarquia superior à unidade de taquigrafia.

Os gerentes mobilizam as estratégias de defesa de negação e de racionalização para suportar o sofrimento. Negar ou evitar o contato com a angústia, o medo e a insegurança, por meio de justificativas e pensamentos valorizados no contexto da gestão organizacional, acabam por suavizar as pressões da Organização do Trabalho.

Os gerentes já apresentaram projetos contendo ações estruturantes e inovações para a melhoria da Organização do Trabalho. No entanto, os gerentes são castrados pelas imposições da casa política, o que gera uma atitude de passividade diante da impossibilidade de uma transformação mais radical na organização do trabalho. Constata-se uma defesa caracterizada pela naturalização do sofrimento ao relatarem que se trata de uma atitude comum das instituições públicas e de uma casa política, devido à falta de 
recursos para atender toda a demanda de investimentos em melhorias na Organização do Trabalho, e que nem sempre se dá prioridade às inovações.

Outra forma de defesa se demonstra na declaração de que alguns problemas enfrentados pelos gerentes decorrem da falta de comprometimento por parte de alguns servidores, bem como das áreas internas, pela morosidade na solução dos problemas que impactam na produção e na viabilização das condições adequadas para a prestação dos serviços.

Constatou-se também a defesa pela valorização da excelência do trabalho da unidade de taquigrafia. $\mathrm{O}$ relato das vantagens da produção desta unidade é mais um modo de negar o sofrimento, vez que mantém registro histórico das grandes decisões legislativas em âmbito nacional, além de disponibilizá-las a toda sociedade, em tempo real, via internet.

Constata-se também a defesa do individualismo demonstrado pela incapacidade de mobilização pelos gerentes. O volume de trabalho é incompatível com a capacidade de produção das pessoas. Cada um preocupase apenas em resistir, visto que não se pode fazer muito em relação ao sofrimento, próprio e alheio (demais gerentes e taquígrafos). A consequência é o conformismo e a resignação.

Mendes e Ferreira (2003) alertam para o fato de que o uso frequente das estratégias defensivas pode tornar-se ineficiente, gerando alienação e fracasso da estratégia, tendo como consequência o adoecimento.

Constataram-se

sintomas psicossomáticos nos gerentes e relações de trabalho adoecidas. A sensação de esgotamento ao final da jornada de trabalho, as alterações no sono, além de dores nas costas e de cabeça caracterizam os adoecimentos psicossomáticos. As relações de trabalho adoecidas caracterizam-se pela racionalização das vantagens da produção excelente, pelo volume de trabalho maior que a capacidade de produção, individualismo e conformismo.

Neste estudo foram identificadas as patologias sociais de sobrecarga de trabalho caracterizada pelo volume de trabalho maior que a capacidade de produção; e a servidão voluntária, demonstrada nas reações de conformis mo concretizado pelas atitudes de resignação, adaptação, integração e eficácia, que implicam na aceitação das adversidades da Organização do Trabalho.

\section{Análise clínica da mobilização do coletivo de trabalho}

A análise clínica da mobilização do coletivo de trabalho revelou que há uma confluência de variáveis que prejudicaram a prática clínica na sua essência, ou seja, a de construir o espaço público de discussão e as estratégias de prevenção do adoecimento, no âmbito da função gerencial.

A construção dos laços afetivos entre os participantes pode ter sido prejudicada por fatores que podem ter gerado um contexto de insegurança quanto à manutenção no cargo gerencial, tais como:

1. A participação do diretor da taquigrafia na Clínica Psicodinâmica do Trabalho;

2. O contexto institucional marcado por mudança na hierarquia da Instituição e da unidade de taquigrafia;

3. A violação do pacto de voluntariado.

Os fatos relatados revelam que ocorrem imprevistos no desenvolvimento do processo de intervenção da Clínica Psicodinâmica do Trabalho e que impactam nos resultados da intervenção. Embora tenham sido observados, de modo criterioso, os procedimentos relativos à organização da pesquisa, à construção e análise da demanda, à instituição de regras de conduta do coletivo de pesquisa, a organização do material de pesquisa coletado e a supervisão. Neste caso, a 
mudança na direção da unidade de taquigrafia e a violação do voluntariado podem ter prejudicado a constituição do espaço da fala e da escuta, a construção dos laços afetivos, tendo impacto negativo na mobilização subjetiva do grupo.

Outro aspecto a ser considerado é o fato de que o gerente faz parte do sistema de gestão. A função gerencial exige comprometimento com a Instituição. Os gerentes defendem o sistema de trabalho vigente, considerando $\mathrm{o}$ padrão de excelência alcançado e o reconhecimento obtido. As pressões do trabalho e a existência de condições de trabalho não ideais faz com que grande parte do tempo do gerente seja dedicada ao alcance dos resultados institucionais. Os gerentes não se permitiram sair do discurso de defesa, utilizando-se das estratégias identificadas para suportar o sofrimento e proteger $\mathrm{o}$ sujeito do adoecimento.

Os gerentes mobilizam-se pelo reconhecimento. Defendem-se do sofrimento gerado pela instabilidade e insegurança do cargo gerencial, pela racionalização e negação, que reforçam a servidão voluntária. Há também sofrimento criativo pelo prazer gerado na busca das soluções dos problemas, com utilização da criatividade do gerente, permitindo enfrentar as imposições e pressões do trabalho. É necessário dinamis mo, iniciativa e criatividade para enfrentar o real do trabalho.

\section{DISCUSSÕES}

$\mathrm{O}$ presente estudo aponta que o envolvimento dos trabalhadores $\mathrm{e}$ as mudanças no contexto institucional, advindas da mobilização subjetiva dos participantes, são essenciais para a Clínica

\footnotetext{
${ }^{6}$ Gaulejac (2007) utiliza o termo "manager", recentemente introduzido no dicionário para designar o gerente ou o administrador de empresas. Neste estudo utilizaremos o termo "gerente".
}

Psicodinâmica do Trabalho, fato que não ocorreu nesta prática clínica.

A Clínica Psicodinâmica do Trabalho também pode ter sido dificultada pela realização do trabalho em uma única unidade de uma única Instituição pública, indicando a necessidade de prosseguir nos estudos com trabalhadores da carreira gerencial abrangendo profissionais de diversas unidades e em diferentes empresas, do âmbito público e privado. Acredita-se que a homogeneidade da Organização do Trabalho será obtida pelo exercício do papel gerencial.

A análise clínica da mobilização do trabalho também revela alguns dos pressupostos apresentados por Gaulejac (2007), Lima (1995) e Ehrenberg (2010). Gaulejac (2007) realiza uma análise crítica da ideologia gerencialista e os efeitos na saúde dos trabalhadores. $\mathrm{O}$ gerente ${ }^{6}$ interioriza a contradição entre capital e trabalho. Por um lado, é contratado para defender o "interesse da empresa", a lógica do lucro/resultado ${ }^{7}$, bem como para aderir às normas e aos valores do sistema capitalista/institucional. Por outro lado, está sujeito a condições de imprevisibilidade da carreira, risco da dispensa, a pressão do trabalho e a competição feroz.

Segundo Lima (1995), os gerentes formam a categoria mais exposta ao discurso ideológico da organização, pois tendem também, mais do que os trabalhadores de escritório e operários, a se identificar com a organização a viver na maior parte do tempo, uma alienação da qual não tem consciência e compensam constantemente a falta de sentido de seu trabalho, através da competição e da agressividade. Neste caso, os gerentes compensam o sentido do trabalho pela excelência nos serviços prestados e respectiva dinâmica do reconhecimento.

\footnotetext{
7 A presente autora propõe a inserção das palavras "resultado e institucional", no texto original de Gaulejac (2007), para abranger a linguagem mais comumente utilizada no âmbito das instituições do setor público.
} 
O gerente pode simbolizar o papel de herói ao adotar uma atitude empreendedora na busca da solução dos problemas, suportar as pressões do trabalho, além de atuar na dupla função de gerente e na linha de produção operacional, visando manter o padrão de excelência pactuado. Tais aspectos podem revelar a cultura de heroísmo generalizado, proposta por Ehrenberg (2010), em que se instala no contexto organizacional contemporâneo uma ideologia do sucesso, uma cultura do ganhe, em que os executivos são os atletas da ascensão social. Neste contexto a empresa é o espaço de realização pessoal; o indivíduo é convidado a conquistar, a progredir, a superar desafios, a buscar patamares de desempenho mais elevados; a atuar com dinamismo e flexibilidade.

Como pontuou Ramos (2013) os gerentes introjetam os valores da organização para alimentarem o ego ideal e acabam por projetar seus ideais nos ideais propostos pela organização onde atuam.

Constatou-se também que, embora não haja coação de violência manifesta para o alcance dos padrões de excelência estabelecidos, os gerentes resignam-se diante de um sistema que reprovam, possivelmente estando sujeitos à servidão voluntária. A vulnerabilidade dos gerentes beneficia mais a empresa, vez que o medo de errar e o reconhecimento da excelência são motores da resignação e reforçam a produtividade. Acredita-se que o medo de errar pode estar associado ao receio de perder a comissão gerencial. Segundo Ferreira (2009) o medo de perder o emprego leva a não expressão do sofrimento. Funciona como um instrumento de gestão, motor da produtividade, poderoso indutor de conformismo e resignação.

Sobre este aspecto, Siqueira (2009) afirma que o fantasma do insucesso ronda os trabalhadores:

... depois de se tornar um superexcecutivo, admirado, sempre no centro das decisões, o indivíduo poderá também vivenciar o sofrimento ocasionado pela perda dessa posição. Então ele estará longe do mundo que criou e que moldou para si (Siqueira, 2009, p. 150).

Segundo Siqueira (2010), a servidão voluntária consiste em uma forma de violência no trabalho, oriunda da precarização do trabalho, que se oculta na autoaceleração, repetição contínua, no uso de medicação para manter o ritmo de trabalho e na pressão por resultados.

A adoção do discurso da excelência pode estar baseada na aceitação das premissas e práticas da gestão organizacional contemporânea, voltadas para o alcance de maior produtividade. Deste modo, vale ainda estudar a dimensão sócio-histórica e seu efeito na Psicodinâmica do Trabalho dos gerentes, conforme premissa apresentada por Garcia (2011).

\section{CONSIDERAÇÕES FINAIS}

Diante do exposto conclui-se que esta prática clínica ficou limitada devido ao modo de estruturação da demanda e a consequente construção dos laços de confiança. Uma vez que a participação voluntária não ocorreu, mesmo tendo sido explicitada na reunião convite. Observou-se que o poder hierárquico se sobressaiu, quando um gestor pediu aos demais que participassem do grupo. A troca de gestores no decorrer da prática clínica também impactou na construção dos laços de confiança, uma vez que começaram a justificar ausências e a pedir o adiamento das sessões. Fato não observado nos estudos de Alves (2014) também com taquígrafos parlamentares.

Quando se observou a organização do trabalho, verificou-se que o gestor é um solucionador de problemas entre os taquígrafos e embora tenha espaço de negociação para discutir os problemas, há pouca flexibilidade para tal, pois a realização das tarefas é muito enrijecida e com alto foco no controle do tempo e na 
excelência da atividade como já descreveu Alves (2014).

Destaca-se, entretanto, que "a mobilização subjetiva é caracterizada pelo movimento do sujeito que viabiliza as capacidades de sentir, pensar e inventar para realizar o trabalho" (Ferreira et al., 2013, p. 101). No grupo observou-se um forte engajamento com o trabalho pela visibilidade que possuem, tanto local, como nacional e internacional. O que acaba sendo fonte de reconhecimento. Entretanto, sofrem com as constantes mudanças na gestão, tal como a que foi vivenciada durante esta prática clínica. Observou-se ainda raiva e frustração pelo descrédito dado às propostas de inovação apresentadas e resistência às mudanças na organização do trabalho. O medo de errar é uma constante entre os gestores, tanto pelo padrão de excelência imputado aos taquígrafos, como pelo erro gerar danos políticos desastrosos. Tudo isso corroborou para o grupo não conseguir se mobilizar e mudar a organização do trabalho, dentro do que fosse possível. O grupo acabou por desistir do espaço de discussão.

Fato corroborado pelas estratégias defensivas, que não puderam ser desfeitas e reconstruídas nesta prática clínica. Observou-se estratégias de defesa de negação, de racionalização, de naturalização do sofrimento, de falta de comprometimento de alguns taquígrafos, de defesa pela valorização da excelência do trabalho da unidade de taquigrafia, mesmo sabendo que volume de trabalho é incompatível com a capacidade de produção das pessoas e por fim $o$ individualismo, geradores de conformis mo e resignação.

A presente pesquisa constitui um dos primeiros estudos envolvendo a prática em Clínica Psicodinâmica do Trabalho na função gerencial e apresenta avanços para a abordagem. Entretanto corrobora os achados de Ramos (2013) ao afirmar que a organização de trabalho, onde os gestores estão inseridos, impede a constituição de um coletivo de gestores, tal como a Clínica
Psicodinâmica preconiza: um espaço de cooperação, solidariedade, de vínculos afetivos e de confiança.

Ao mesmo tempo aponta a necessidade de realizar estudos futuros para aprofundar os resultados encontrados. Sugere-se realizar pesquisas abrangendo:

1. O impacto do envolvimento dos trabalhadores e o contexto institucional na Clínica Psicodinâmica do Trabalho;

2. A ampliação do estudo em diferentes amostras;

3. O papel da Psicodinâmica do Trabalho gerencial no processo de manutenção da Organização do Trabalho contemporânea;

4. A vulnerabilidade da função gerencial e a defesa da servidão voluntária;

5. O impacto da dimensão sóciohistórica na psicodinâmica da função gerencial e sua influência no processo de aceitação/manutenção de modelos de gestão organizacional com foco na produtividade.

\section{REFERÊNCIAS}

Alves, J. J. (2014). Mobilização Subjetiva para o Prazer-Sofrimento no Trabalho dos Taquígrafos Parlamentares: Uma Prática em Clínica Psicodinâmica da Cooperação. Dissertação de Mestrado, Universidade de Brasília, DF, Brasil, 106 p.

Bendassolli, P. F., \& Soboll, L. A. P. (2011). Introdução às Clínicas do Trabalho. In P. F. Bendassoli \& L. A. P. Soboll, (orgs). Clínicas do trabalho. (pp. 3-21). São Paulo: Atlas.

Dejours, C. (1992). A loucura do trabalho: estudo de psicopatologia do trabalho. (5 ed, ampliada, A. I. Paraguay \& L. L. Ferreira Trads.) São Paulo: Cortez, Oboré. 168 p.

Dejours, C. (2008) avant-propos para a edição brasileira/addendum, da psicopatologia à Psicodinâmica do Trabalho. In S. Lancman \& L. I. 
Sznelwar (orgs). Christophe Dejours: da psicopatologia à Psicodinâmica do Trabalho (pp. 17-23/49-106). Rio de Janeiro: Editora Fiocurz. Brasília: Paralelo 15.

Dejours, C., \& Bégue, F. (2010). Suicídio e Trabalho: o que fazer. Brasília: Pararelo 15.

Duarte, F. S. (2014). Dispositivos para a escuta clínica do sofrimento no trabalho: Entre a clínica da cooperação e das patologias. Dissertação de Mestrado, Universidade de Brasilia, DF, Brasil, $142 \mathrm{p}$.

Eberle, A. D.; Soboll, L. A. P; Horst, A. C. (2010). Avaliação comparativa de resultados e assédio moral organizacional: concorrência generalizada, individualismo e adoecimento no trabalho. In A. M. Mendes, A. R. C. Merlo, C. F. Morrone \& E. P. Facas (Orgs). Psicodinâmica e Clínica do Trabalho: temas, interfaces e casos brasileiros (pp. 519-535). Curitiba: Juruá.

Ehrenberg, A. (2010). O culto da performance: da aventura empreendedora à depressão nervosa. Aparecida-SP: Ideias e letras.

Facas, E. P. (2009). Estratégias de mediação do sofrimento no trabalho automatizado: estudo exploratório com pilotos de trem de Metrô do Distrito Federal. Dissertação de Mestrado, Instituto de Psicologia, Universidade de Brasilia, Brasilia.

Ferreira, J. B. (2009). Perdi um jeito de sorrir que tinha: violência, assédio moral e servidão voluntária no trabalho. Rio de Janeiro: 7 Letras.

Ferreira, J. B., Mendes, A. M., Lima, S. C da C., Facas, E. P. \& Ghizoni, L. D. (2013). Entre a mobilização subjetiva e a subtração do desejo: estudos com base na psicodinâmica do trabalho. In A. R. C. Merlo; A. M. Mendes \& R. D. de Moraes (Orgs.). O sujeito no trabalho: entre a saúde e a patologia.
(Biblioteca Juruá de Psicodinâmica e Clínica do Trabalho, pp. 101-118). Curitiba: Juruá.

Freitas, L. G. (2006). Saúde e Processo de Adoecimento no Trabalho dos Professores em Ambiente Virtual. Tese de Doutorado, Universidade de Brasîlia, Brasîlia.

Garcia, W. I. (2011). Análise Psicodinâmica do Trabalho no Tribunal de Justiça do Amazonas: uma aplicação da clínica do trabalho $e$ da ação. Manaus, AM. Dissertação de Mestrado. Universidade Federal do Amazonas, Manaus, AM, Brasil, 109 p.

Gaulejac, V. de. (2007). Gestão como doença social: ideologia, poder gerencialista e fragmentação social. Aparecida-SP: Ideias \& Letras.

Ghizoni, L. D. \& Mendes, A. M. (2014a). Dispositivos para uma escuta clínica do sofrimento no trabalho dos catadores de materiais recicláveis. Contextos Clínicos, 7(1),15-26.

Ghizoni, L. D.; Mendes, A. M. (2014b). Mobilização de um coletivo de catadores: pratica em clínica psicodinâmica da cooperação. Cadernos de Psicologia Social do Trabalho, 17(2), 206-223.

Ghizoni, L. D., Mendes, A. M. \& Corgozinho, J. P. (2013). Uma proposta brasileira para a Clínica Psicodinâmica do Trabalho. In V. de L. D. C. Schlindwein (Org.). Saúde mental e trabalho na Amazônia: múltiplas leituras sobre prazer e sofrimento no trabalho. Vol I, Porto Velho-RO: EDUFRO, p. 25-39.

Heloani, R. \& Lancman, S. (2004). Psicodinâmica do Trabalho: o método clínico de intervenção e investigação. Revista Produção. 14 (3), 77-86.

Lima, M. E. A. (1995). Os equívocos da excelência. Petrópolis-RJ: Vozes.

Martins, S. R. (2009). Clínica do Trabalho. São Paulo: Casa do Psicólogo. 
Mendes, A. M. (2007). Psicodinâmica do Trabalho: teoria, métodos e pesquisas . São Paulo: Casa do Psicólogo.

Mendes, A. M. (2008). A Organização do trabalho como produto da cultura e a prevenção do estresse ocupacional: o olhar da Psicodinâmica do Trabalho. In A. Tamayo (Org.). Estresse e Cultura organizacional (pp. 164-191). São Paulo: Casa do Psicólogo: All Books.

Mendes, A. M. (2014). Escuta analítica do sofrimento e o saber-fazer do clínico do trabalho. In: A. M. Mendes; R. D. Moraes \& A. R. C. Merlo (Orgs.). Trabalho e sofrimento: práticas clínicas e políticas (pp. 65-80). Curitiba: Juruá. 260 p.

Mendes, A. M \& Ferreira, M. C. (2003). Trabalho e riscos de adoecimento: $o$ caso dos auditores fiscais da Previdência Social Brasileira. Brasília: Ler, Pensar, Agir.

Mendes, A. M \& Morrone, C. (2010). Trajetória e pesquisas brasileiras sobre prazer e sofrimento no trabalho. In A. M. Mendes, A. R. C. Merlo, C. F. Morrone \& E. P. Facas (Orgs). Psicodinâmica e Clínica do Trabalho: temas, interfaces e casos brasileiros (pp. 29-51). Curitiba: Juruá.

Mendes, A. M. \& Araújo, L. K. R. (2012). Clínica Psicodinâmica do Trabalho: $o$ sujeito em ação. Curitiba: Juruá.

Ramos, L. V. (2013). O Coletivo de Trabalho dos Gestores Intermediários de uma Empresa Multinacional: a abordagem da psicodinâmica do trabalho. Dissertação de Mestrado, Universidade de Brasilia, DF, Brasil, $95 \mathrm{p}$.

Siqueira, M. V. S. (2009). Gestão de Pessoas e Discurso Organizacional: crítica à relação indivíduo-empresa nas organizações contemporâneas. Curitiba: Juruá.

Siqueira, M. V. S. (2010). Gestão, violência e servidão nas organizações: contribuições da sociologia clínica e da Psicodinâmica do Trabalho. In A. M. Mendes, A. R. C. Merlo, C. F. Morrone
\& E. P. Facas (Orgs). Psicodinâmica e Clínica do Trabalho: temas, interfaces e casos brasileiros (pp. 165 - 177). Curitiba: Juruá.

Data de submissão: 13/07/2017

Data de aceite: 30/08/2017 